\title{
Risk Evaluation Model of Supply Chain Logistics Service Outsourcing Based on FAHP
}

\author{
Yiling Peng, a, Daqiang Chen ${ }^{1, \mathrm{~b}}$, Lingling Zhang ${ }^{1, \mathrm{c},}$ Tingyun $\mathrm{Wu}^{1, \mathrm{~d}}$, \\ Danzhi Sun ${ }^{2, \mathrm{e}}$ \\ ${ }^{1}$ School of Computer Science \& Information Engineering, Zhejiang \\ Gongshang University, Hangzhou 310018, China \\ ${ }^{2}$ Zhejiang Scientific Research Institute of Transport, Hangzhou 310006, \\ China \\ ayiling_peng@163.com, b chendaqiang@mail.zjgsu.edu.cn, \\ ${ }^{c}$ zhanglinglinglinda@163.com, .'790161079@qq.com, ${ }^{e}$ \\ 281148262@qq.com
}

\begin{abstract}
In the background of economic globalization, logistics service outsourcing has become one of the preferred. In this paper, through field research, large amounts of information access, analysis, consolidation effect of logistics outsourcing business related factors, build the supply chain enterprise logistics outsourcing risk index system, and has carried on the quantification, designs the corresponding evaluation system, and then using the fuzzy hierarchy analysis method (FAHP method) to index system for the calculation of weight and quantitative evaluation. For the eventual construction of enterprise logistics outsourcing decision of supply chain enterprises logistics outsourcing risk evaluation system and the theoretical basis for.
\end{abstract}

Keywords: FAHP, service outsourcing, supply chain, risk assessment.

\section{Introduction}

These days, a vast number of enterprises prefer service outsourcing, so that they can strengthen their core competency to meet all kinds of customers' requirements and to survive in the unstable market. Supply chain management (SCM) outsourcing is a recent trend, usually adopted to gain lower production costs, but also can be used to reduce core organizational risk. In fact, outsourcing has become very widespread in the last decade and it changes from peripheral business functions in the past, to more vital business functions being outsourced today [1][2]. However, unsuccessful experiences that accrue undesirable consequences for client firms have been often reported [3][4], Meanwhile, the service outsourcing is immature. According to a survey data, there are more than $30 \%$ of customers complaining about the risk problems of the outsourcing vendors. There is no doubt that it has attracted considerable and increasing attention in both 
industry and academia, as their activities and requirements become increasingly complex and exist something risky[5]. Supply chain management outsourcing involves many risks including disruption, product failure, information risk or other forms of risk [6]. While these risks can be daunting, doing business requires acceptance of some level of risk within the organization's area of expertise. If the risks are not effectively controlled or calculated, it will not only come into effect, but also lead to a loss of competitive advantage. Therefore, enterprises cannot take risk in ignoring the risk assessment system which can be a significant competitive edge in the market.

In the previous outsourcing risks researches, investigators mainly focus on information system outsourcing and logistics outsourcing. Organizations outsourcing their services might not be solely concerned with cost [7]. Satty and Luis [1] [8]argue that the risk practices are better represented by identifying their priorities, because risk events whose effects are difficult to model in probabilistic ways are nevertheless describable in terms of qualitative scales. In 1996, Earl reported 11 kinds of risks in IS outsourcing, including the possibility of weak vendor management skills, IS services, contracts and relationships with IS suppliers [9]. Aubert etc. [10] analyzed the extreme case of a company whose supplier provided service of such poor quality that all the outsourced operations had to be brought back in house.

\section{Establishment of Evaluation Framework}

Logistics Outsourcing Risk identification and its influencing factors. After a great deal of relevant literature preliminary inquiries and business research, logistics outsourcing risk factors can be identified. Internal sources of supply chain uncertainty include capacity availability, information delays, and regulatory compliance [11]. External sources include competitor actions, political environment, market price fluctuations, uncertain costs, and supplier quality [12]. For now, supply chain logistics outsourcing risk arises primarily can be list as:

- Management risk: Management risk can be divided into six areas, including outsourcing contract risk, cooperation risk of instability, integration of corporate culture, personnel management risk of conflict, outsourcing impact on core business.

- Operational risk: Faced to hotly-contested market, the cost of enterprise is importance to supply chain enterprises when considering the operational risk in the process of choosing the TPL providers. And the operational risk can also be composed of the following three aspects including transportation costs, warehousing costs and other costs.

- Information risk: During outsourcing, there will exit asymmetric information between the cooperative enterprises due to lack of information sharing, poor communication, feedback delay and information distortion. In the case of asymmetric and incomplete information, the supply chain enterprise is in a more disadvantageous position than the TPL providers.

- Credit and Financial risk: Credit and financial risk refers to financial 
situation and industry credibility of the TPL.

- Service capabilities risk: Service capabilities includes transportation network coverage, storage capacity, emergency handling capabilities, rapid response capability, information systems complexity, value-added service capabilities, and staff quality.

- QOS risk: QOS risk refers to punctuality rate, accuracy rate, damaged cargo rate, and communication skills which can examine the quality of service third party logistics enterprises.

Establishment of Evaluation Framework. In order to satisfy the requirements of hierarchical structure, principled, and apply to the widest possible supply chain enterprises, the supply chain logistics outsourcing risk evaluation framework can be established as follows based on scientific principles, systematic principle, the principle of comprehensiveness, operability principle and the principle of dynamic, as Table 1 shows. The explanation of each index is listed as follows:

Table 1. SUPPLY CHAIN LOGISTICS OUTSOURCING RISK EVALUATION FRAMEWORK

\begin{tabular}{|c|c|c|}
\hline Purpose & Criteria & Index \\
\hline \multirow{23}{*}{$\begin{array}{c}\text { Supply } \\
\text { chain } \\
\text { logistics } \\
\text { outsourcin } \\
\text { g risk } \\
\text { evaluation } \\
\text { framework }\end{array}$} & \multirow{5}{*}{ Management Risk (A) } & outsourcing contract risk (A1) \\
\hline & & cooperation risk of instability (A2) \\
\hline & & integration of corporate culture (A3) \\
\hline & & integration of corporate culture (A4) \\
\hline & & outsourcing impact on core business (A5) \\
\hline & \multirow{3}{*}{ Operational risk (B) } & transportation costs (B1) \\
\hline & & warehousing costs (B2) \\
\hline & & other costs (B3) \\
\hline & \multirow[t]{2}{*}{ Information Risk (C) } & $\begin{array}{l}\text { construction level of Information-sharing } \\
\text { mechanism (C1) }\end{array}$ \\
\hline & & information leakage (C2) \\
\hline & \multirow{7}{*}{$\begin{array}{l}\text { Service capabilities } \\
\text { risk (D) }\end{array}$} & service capabilities risk (D1) \\
\hline & & storage capacity (D2) \\
\hline & & emergency handling capabilities (D3) \\
\hline & & rapid response capability (D4) \\
\hline & & information systems complexity (D5) \\
\hline & & value-added service capabilities (D6) \\
\hline & & staff quality (D7) \\
\hline & \multirow{4}{*}{ quality of service $(E)$} & punctuality rate (E1) \\
\hline & & accuracy rate (E2) \\
\hline & & damaged cargo rate (E3) \\
\hline & & communication skills (E4) \\
\hline & \multirow{2}{*}{$\begin{array}{l}\text { Credit and Financial } \\
\text { Risk (F) }\end{array}$} & financial situation of the TPL (F1) \\
\hline & & industry credibility of the TPL (F2) \\
\hline
\end{tabular}




\section{Risk evaluation model of supply chain logistics service outsourcing based on FAHP}

In order to achieve the purpose of this study and reflect the degree of risk of logistics service outsourcing objectively and scientifically, the theory including risk evaluation model of supply chain logistics service outsourcing, basing on the study of the risk management and risk evaluation methods has been put forward. Meanwhile, the detailed interpretation of risk factors and essence of other theories of risk evaluation also provide a reference for above theory. So essence of this theory is depicting the role of each risk factor which plays in the overall, and it should be integrated into the degree of importance of each risk factor to the actual situation of enterprises. SC risk-based partner selection developed a FAHP model to partnership selection in the formation of virtual enterprises [13]. Therefore, this paper will select the method of Fuzzy Analytic Hierarchy Process by comprehensive comparison about the contents of this paper.

Establish a hierarchy index. After analyze and determine the evaluation indexes, various factors of evaluation indexes should be stratified, and the top layer is the goal, while the middle layer and the bottom are relevant factors for the overall goal.

Establish precedence relational matrix layers. Establish matrix with reference to relative importance of the factors in each layer relative to that in the upper layer. The set of influencing factors can be expressed as the following formula: $Y=\left\{y_{1}, y_{2}, \cdots, y_{m}\right\}, m$ is the index number of set. precedence relational matrix layers $Y=\left(y_{i j}\right)_{m \times n}$ can be calculated using the procedure:

$$
y_{i j}=\left\{\begin{array}{l}
0.5, s(i)=s(j) \\
1.0, s(i)>s(j) \\
0, s(i)<s(j)
\end{array}\right.
$$

where $S(i)$ and $S(j)$ indicate the relative importance of $y_{i}$ and $y_{j}$ respectively. $i$ is the index number of columns; and $j$ is the index number of rows.

This way would solve the problem greatly which is difficult to quantify proportion criteria from 1 to 9. Precedence relation matrix layers $Y$ are transformed into fuzzy consistent matrix $R$. At first, get the summation of $Y$ by row, $\quad r_{i}=\sum_{k=1}^{m} y_{i k}, i=1,2, \ldots \ldots, m$, then it should be transformed as $r_{i j}=\frac{r_{i}-r_{j}}{2 m}+0.5$

According to the definition, if $r_{i j}=r_{i k}-r_{j k}+0.5, R=\left(r_{i j}\right)_{m \times n}$ can satisfy the condition of fuzzy consistent matrix.

Single-hierarchy sorting. Use judgment matrix of fuzzy consistent matrix to calculate hierarchy sort by importance of various factors, remembering to make 
weight indexes normalized at the same time. This paper take root method to calculate by completing the following steps:

$$
\begin{aligned}
& S_{i}=\prod_{j=1}^{m} r_{i j}, i=1,2, \ldots \ldots, m, m \text { is the number of the factors in layer of } k \text { ) } \\
& \overline{w_{i}}=\left(S_{i}\right)^{\frac{1}{m}} \\
& \boldsymbol{w}_{p i}^{k}=\frac{\overline{\boldsymbol{w}_{i}}}{\sum_{j=1}^{m} \overline{w_{j}}}
\end{aligned}
$$

where $w_{p_{i}}^{k}$ is the weights of element $i$ in $k$ layer, while $i$ belong to element $p$ which is in upper layer. Then, $w_{p}^{k}=\left(w_{p_{1}}^{k}, w_{p_{2}}^{k}, \ldots w_{p_{m}}^{k}\right)^{T}$ can be drawn.

Total sorting. Assuming there is $n$-tier hierarchy of ladder, $p$ is the element of $k$ layer and $w_{i}(i=n)$, is the final weight of each factor of the bottom, where $w_{i}=w_{p i}^{n} w_{p_{i}}^{n-1} \ldots w_{p_{i}}^{1}, 1 \leq k \leq n$.

Determine weights. Design of the questionnaire for experts: After construct hierarchical index system, expert questionnaire is designed to determine the appropriate weights by rating scale from 1 to 9 . A total of 50 expert questionnaires were sent, which involves logistics experts in this field and experienced staff from related logistic companies. The 44 questionnaires were sent back totally, 41 of the questionnaires are effective, its effective rate reached 78\%.the explanation of rating scale and expert questionnaires detailed in Appendix.

Questionnaire data processing: After the raw data from questionnaires had been pre-processed, it would be imported into EXCEL spreadsheet for further analysis. In reality, for the limited quantity characteristics of expert questionnaires, the way of t-distributions in a probability plot to make data normalized. Then, according to the corresponding confidence intervals for each data from scoring table, it can be easy to obtain fuzzy range of values.

FAHP method to determine the index weight: According to the above five steps of FAHP method, in the step (3) and step (4), this paper use MATLAB software to calculate the fuzzy consistent matrix and corresponding index weights respectively. Taken first level evaluation index weight as an example, the results is listed in Table 2, and we can get a table about supply chain logistics outsourcing risk evaluation index weights as Table 3 shows.

Table 2. SUPPLY CHAIN LOGISTICS OUTSOURCING RISK EVALUATION: FIRST LEVEL EVALUATION

\begin{tabular}{llllllll}
\hline & A & B & C & D & E & F & $\begin{array}{l}\text { Weigh } \\
t\end{array}$ \\
\hline A & 0.5 & 0.3 & 0.3 & 0.2 & 0.6 & 0.3 & 0.1265 \\
& & 5 & & 5 & 5 & 5 & \\
\hline
\end{tabular}




\begin{tabular}{llllllll}
\hline B & 0.6 & 0.5 & 0.4 & 0.4 & 0.8 & 0.5 & 0.1789 \\
& 5 & & 5 & & & & \\
C & 0.7 & 0.5 & 0.5 & 0.4 & 0.8 & 0.5 & 0.2008 \\
& & 5 & & 5 & 5 & 5 & \\
D & 0.7 & 0.6 & 0.5 & 0.5 & 0.9 & 0.6 & 0.2254 \\
& 5 & & 5 & & & & \\
E & 0.3 & 0.2 & 0.1 & 0.1 & 0.5 & 0.2 & 0.0895 \\
& 5 & & 5 & & & & \\
F & 0.6 & 0.5 & 0.4 & 0.4 & 0.8 & 0.5 & 0.1789 \\
& 5 & & 5 & & & & \\
\hline
\end{tabular}

Table 3.

SUPPLY CHAIN LOGISTICS OUTSOURCING RISK EVALUATION INDEX WEIGHTS $(* 10-2)$

\begin{tabular}{lccccc}
\hline $\begin{array}{l}\text { Index }\left(v_{i}\right. \\
\text { ) }\end{array}$ & $\begin{array}{l}\text { Weigh } \\
\mathrm{t}\end{array}$ & $\begin{array}{l}\text { Index }\left(v_{i}\right. \\
)\end{array}$ & $\begin{array}{l}\text { Weigh } \\
\mathrm{t}\end{array}$ & $\begin{array}{l}\text { Index }\left(v_{i}\right. \\
)\end{array}$ & $\begin{array}{c}\text { Weigh } \\
\mathrm{t}\end{array}$ \\
\hline A1 & 2.44 & $\mathrm{C} 1$ & 10.04 & $\mathrm{D} 7$ & 4.55 \\
$\mathrm{~A} 2$ & 3.69 & $\mathrm{C} 2$ & 10.04 & $\mathrm{E} 1$ & 1.55 \\
$\mathrm{~A} 3$ & 2.79 & $\mathrm{D} 1$ & 3.19 & $\mathrm{E} 2$ & 2.69 \\
$\mathrm{~A} 4$ & 2.12 & $\mathrm{D} 2$ & 2.15 & $\mathrm{E} 3$ & 1.18 \\
A5 & 1.61 & $\mathrm{D} 3$ & 3.80 & $\mathrm{E} 4$ & 3.53 \\
B1 & 7.93 & $\mathrm{D} 4$ & 3.80 & $\mathrm{~F} 1$ & 8.94 \\
B2 & 6.93 & D5 & 3.38 & $\mathrm{~F} 2$ & 8.94 \\
B3 & 3.03 & D6 & 1.66 & & \\
\hline
\end{tabular}

\section{Empirical Analysis of Case}

At the risk evaluation stage of value, take secondary level evaluation index as an example, such as the transport of costs. Assuming there is the manufacturing industry, the quantized value of the transport prices and the unit of price is Yuan per ton per kilometer. The transport price is divided into five ratings, like 0.3 Yuan, 0.3 to 0.5 Yuan, 0.5 Yuan to 0.7 Yuan, 0.7 Yuan to 0.9 Yuan, 0.9 Yuan above. The score of risk is sorted in ascending, representing integer from 1 to 5 . According to score (percentile, per 20 points a rating) converted into the corresponding risk value, multiplied by the corresponding weights, the final value is the size of risk.

Assuming transport price of TPL service providers is 0.66 and then its score should be 56. So, equivalent score of risk is $56 / 20=2.8$. While its weight is assumed to be 0.07 , the final the score of risk is 0.196 . Quantitative approach to storage capacity is similar to the above method. It owns two indexes: storage area and storage handling capacity. These indexes can be quantified as below: Area can be divided into five degrees: 30000 or more, 10,000 30,000 square meters, 5,000 to 10,000 square meters, 3,000 to 5,000 square meters, 3,000 square meters less . And handling capacity can be also divided into five ranges from high to low .If the weight of area is 0.3 , handling capacity is 0.7 and two initial score of risk is 2and 4, the total weight of the storage capacity is 0.06 . The final score of 
risk is easy to be calculated as $(0.3 * 2+0.7 * 4) * 0.06=0.204$.

For other qualitative secondary level evaluation indexes, it can be set the score of risk under own judgment of TPL service providers. Next, calculate the final score of risk by using above process. The sum of these values is the total value of risk when the TPL service providers accept outsourcing business.

\section{Conclusion}

Our future researches about our assessment model will be as follows:

- Improve the risk index system. We will perfect our risk indexes through rechecking the materials, researching enterprises, and many other ways.

- Improve the method of quantification. The data in this research is simulated, so we manage to find an appropriate method and a realistic data to support this risk assessment system.

Improve the assessment system. Taking the subjective and objective reasons into consideration and improving the FAHP algorithm.

\section{Acknowledgements}

This study is supported by the National Natural Science Foundation of China (71403245), Zhejiang Provincial Natural Science Foundation of China (LQ12G01006), the Key Foundation of Philosophy and Social Science of Zhejiang Province (14NDJC139YB), Zhejiang Gongshang University's "Hope cup" Students Extracurricular Academic Science and Technology Work Competition Project, Zhejiang Gongshang University Students' Innovation Project and Zhejiang Provincial University Students Scientific Innovative Project (2013R408030).

\section{References}

[1] M.C. Tsai, Y.S. Su: Journal of Air Transport Management, Vol. 8 (20020, p. 373.

[2] C.K.M. Lee, Y.C. Yeung: Industrial Management and Data Systems, Vol. 112 (2012), p. 541.

[3] B. Bahli, S. Rivard: Journal of Information Technology, Vol. 18 (2003), p. 211.

[4] M.C. Tsai, C.H. Liao and C.S. Han: Supply Chain Management: An International Journal, Vol.13 (2008), p. 415.

[5] C.S. Tang: International Journal of Production Economics, Vol.103 (2006), p.451.

[6] C. Lucas, G. Mitra and C.A. Poojari: Journal of the Operational Research Society, Vol.58 (2007), p. 1397

[7] O.K. Ngwenyama, N. Bryson: European Journal of Operational Research, Vol. 115 (1999), p. 351. 
[8] D.X. Wu, D.D. Wu, Y.D. Zhang and D.L. Olson: Information Science, Vol. 235 (2013), p. 242.

[9] Z.X. Liu, J. Xu, Y. Li, X.J. Wang and J.B. Wu: Kybernetes, Vol. 41 (2012), p. 1200.

[10] B. Aubert, M. Patry, and S. Rivard: Wirtschaftsinformatik, Vol. 45 (2003), p.181.

[11] F. Cucchiella, M. Gastaldi: Journal of Manufacturing Technology Management, Vol. 17 (2006), p. 700.

[12] D.L. Olson, D.S. Wu: Supply Chain Management: An International Journal, Vol. 16 (2011), p. 401.

[13] R. Narasimhan, S. Talluri and S.K. Mahapatra: Decision Sciences, Vol. 37 (2006), p. 577. 